\title{
ARQUITETURA FOLIAR EM POPULAÇÕES DE MILHO DE CICLOS CONTRASTANTES
}

\section{BIOENG}

\author{
J. Borella ${ }^{1 *}$, R. Leschewitz ${ }^{2}$, J. W. Trautenmüller ${ }^{1}$
}

${ }^{1}$ UFPR - Universidade Federal do Paraná, Programa de Pós-Graduação em Agronomia Produção Vegetal, Curitiba, PR, Brasil.

${ }^{2}$ Empresa Mato-Grossense de Pesquisa, Assistência e Extensão Rural, Claudia, MT, Brasil.

Article history: Received 21 May 2019; Received in revised form 30 May 2019; Accepted 05 June 2019 ; Available online 24 June 2019.

\section{RESUMO}

O conhecimento da arquitetura foliar, bem como área foliar de populações crioulas é importante para poder selecionar materiais promissores para futuros cruzamentos. $\mathrm{O}$ trabalho teve como objetivo determinar o perfil das plantas de milho de ciclo superprecoce, precoce e tardio em seus diferentes estágios vegetativos, levando em consideração a disponibilidade hídrica e determinar a área foliar. A população usada no experimento era composta por 21 acessos, sendo sete para cada ciclo (superprecoce, precoce e tardio). Foram feitas avaliações de comprimento da folha, largura de folha, altura de planta, área foliar por estádio vegetativo, altura de inserção da espiga, comprimento e ramificações do pendão, comprimento de internódios, diâmetro do colmo. Os dados foram submetidos à análise de variância, ao grau de significância de 5\% de erro pelo teste de Tukey. Os genótipos de ciclo superprecoce, precoce e tardio avaliados nos anos 1 e 2 apresentam arquitetura foliar de pentágono irregular invertido. O maior incremento em área foliar ocorre a partir do estágio V10 em populações crioulas para os diferentes ciclos. A disponibilidade de água no solo afeta diretamente a área foliar principalmente no período vegetativo e, consequentemente, componentes como diâmetro do colmo e distância de internódios.

Palavras-chave: área foliar, melhoramento genético, Zea mays.

\section{FOLIAR ARCHITECTURE IN CORN POPULATIONS OF CONTRASTING CYCLES}

\begin{abstract}
Knowledge of leaf architecture as well as foliar area of landraces populations is important in order to select promising materials for future crosses. The objective of this work was to determine the profile of the superprecocious, early and late cycle corn plants in their different vegetative stages taking into account the water availability and determine the leaf area. The population used in the experiment consisted of 21 accesses, seven for each cycle (superprecocious, precocious and late). Leaf length, leaf width, plant height, leaf area per vegetative stage, height of spike insertion, length and ramifications of the tassel, length of internodes, diameter of the stem were evaluated. The collected data were submitted to analysis of variance, to the degree of significance of $5 \%$ of error by the test of Tukey. The superprecocious, precocious and late cycle genotypes evaluated in years 1 and 2 present inverted irregular pentagon leaf architecture. The greatest increase in leaf area occurs from the V10 stage in landraces populations for the different cycles. The availability of water in the
\end{abstract}

\footnotetext{
*borella.juli@gmail.com
} 
soil directly affects the leaf area mainly in the vegetative period and consequently components such as stalk diameter and distance of internodes.

Keywords: leaf area, genetic improvement, Zea mays.

\section{INTRODUÇÃO}

A cultura do milho é um dos principais commodities para a agricultura Brasileira, a sua produtividade máxima está ligada com as condições de manejo realizadas, seja adubação (KAPPES et al., 2013), disponibilidade hídrica, até mesmo a incidência luminosa (MENDES et al., 2013). Para as culturas utilizarem de forma eficiente à radiação, tem-se a influência do índice de área foliar, parâmetros físicos, biológicos, que irão determinar a absorção da radiação incidente (REIS et al., 2013).

O ciclo de um genótipo de milho é caracterizado de acordo com o número de dias desde a semeadura até a maturidade fisiológica, em função da temperatura. As cultivares de milho de ciclo superprecoce, necessitam de menor soma térmica para iniciar a floração, inferior a $830^{\circ} \mathrm{C}$ dia, as cultivares de ciclo precoce superior a $831^{\circ} \mathrm{C}$ dia, e tardios necessitam de acúmulo superior a $890^{\circ} \mathrm{C} \mathrm{dia}^{-1}$ (MARTINS et al., 2012). Porém, cultivares precoces requerem maior densidade de plantas para expressar seu potencial de rendimento. Isso ocorre devido apresentarem menor estatura, folhas menores, consequentemente menor área foliar por planta e menos sombreamento do dossel da cultura (MUNDSTOCK, 1977).

Ao longo da cultura é possível evidenciar estádios de desenvolvimento caracterizados por alterações morfológicas conforme condições do ambiente. $\mathrm{O}$ período de dias de uma fase fenológica varia de região para região, de ano para ano, devido variações climáticas, como temperatura do ar e do solo, umidade relativa, chuva, radiação solar e fotoperíodo (VILHEGAS, 2001).

A radiação fotossinteticamente ativa é afetada pela escolha do arranjo de plantas, dessa forma, a utilização de espaçamento adequado influência diretamente sobre o crescimento e desenvolvimento da cultura do milho (BRACHTVOGEL et al., 2009). Seu uso efetivo pelas plantas depende, além de sua disponibilidade, da capacidade delas de intercepta-la em seu dossel.

O aumento do rendimento de grãos da cultura do milho neste século ocorreu devido ao melhoramento genético, selecionando plantas com menor estatura, menores pendões, menos número de folhas, colmos mais fortes, possibilitando menor espaçamento entre linha e plantas. Assim, foi possível a ocorrência deste aumento de produtividade, com grande contribuição de genótipos que toleram maior densidade de plantas (STRECK \& SCHWAB, 2016).

A maior produtividade para o milho tem sido atribuída à produção de massa seca (LIMA et al., 2016). Desta forma, a taxa de área foliar é fator importante para caracterizar os teores de massa seca, com maior crescimento inicial e maior área foliar, a cultura pode aproveitar maior quantidade de radiação solar disponível no inicio do ciclo, sendo esta interceptada para a fotossíntese (OLIVEIRA et al., 2013; DEPRÁ et al., 2016).

Em alguns genótipos ocorre maior direcionamento de fotoassimilados para a produção de folhas durante a fase inicial de crescimento, resultando em maior potencial produtivo, devido o melhor aproveitamento de radiação solar disponível no início do ciclo da planta, incrementando da disponibilidade de carboidratos para a diferenciação de maior número de espigas. Contudo, o rendimento de grãos por hectare depende também da capacidade das culturas de alocar fotoassimilados à estrutura de interesse econômico (KAPPES et al., 2013; OLIVEIRA et al., 2013).

Os elementos como radiação, temperatura, vento e umidade influenciam 
a cultura do milho. Interferindo nas características morfológicas de um dossel da cultura e na eficiência de processos fisiológicos, os quais definem a quantidade de fotoassimilados que uma planta produz. Caso ocorram condições adversas, por exemplo, déficit hídrico, as plantas apresentam alteração na temperatura foliar, redução na absorção de $\mathrm{CO}_{2}$, resistência aerodinâmica, resistência da cultura à evaporação, assim afeta negativamente a taxa de fotoassimilados, ou seja, o crescimento e desenvolvimento da cultura (SILVA et al., 2012).

A redução da expansão celular é o primeiro efeito ao déficit hídrico, dependendo do grau pode até limitar a divisão celular (KUNZ et al., 2007). Portanto, a deficiência hídrica afeta o crescimento e desenvolvimento das

\section{MATERIAL E MÉTODO}

Os experimentos foram realizados nos anos agrícolas 2010/11 e 2011/12 na área experimental da Universidade Federal de Santa Maria, Campus de Frederico Westphalen, com as coordenadas geográficas: $27^{\circ} 23^{\prime} 40^{\prime}$ 'S, 5326'10' $\mathrm{W}$, altitude de $490 \mathrm{~m}$, precipitação média anual de $1800 \mathrm{~mm}$. O clima da região de acordo com a classificação de Köppen é Subtropical úmido (Cfb) (ALVARES et al., 2014), com regime de chuvas equilibrado, porém, à redução da precipitação na estação do inverno, média anual entre 1.700 e $1.900 \mathrm{~mm} \mathrm{e}$ temperatura média entre 20 e $23^{\circ} \mathrm{C}$ (ROSSATO, 2014).

Os acessos de milho crioulo foram coletados no município de Seberi, RS ( $27^{\circ} 28^{\prime} 20^{\prime}$ 'S e $53^{\circ} 24^{\prime} 10^{\prime \prime}$ 'W), em fevereiro de 2010, totalizando 21 acessos coletados, sendo sete populações por tipo de ciclo (superprecoce, precoce e tardio). As populações amostradas foram embaladas em sacos de papel encerado, cada acesso recebeu uma numeração conforme sequência específica das propriedades amostradas, posteriormente foram enviadas para laboratório. plantas, devido ao estresse e decréscimo do índice de área foliar (NASCIMENTO et al., 2011), acarretado pelo enrolamento das folhas, reduzindo a área de absorção da radiação fotossinteticamente ativa da planta (ENDRES et al., 2010). Sendo que o déficit durante o período vegetativo (V12) mais afeta a cultura quanto sua fisiologia e produção (GARCIA et al., 2008).

O conhecimento da arquitetura foliar predominante nas populações de milho contribui para escolha dos acessos que poderão futuramente serem utilizados em cruzamentos. Dessa forma o presente trabalho objetivou determinar o perfil das plantas de milho de ciclo superprecoce, precoce e tardio em seus diferentes estágios vegetativos e determinar a área foliar em diferentes épocas de plantio.

O preparo do solo foi realizado de forma convencional com duas gradagens, as semeaduras foram efetuadas em Latossolo vermelho aluminoférrico (SANTOS et al., 2013) em dois anos agrícolas consecutivos (2010-11 e 201112). As datas de semeadura foram 17/12/2010 e 17/09/2011. O delineamento utilizado foi em blocos casualizados, composto por três blocos com uma planta de avaliação cada, o espaçamento utilizado foi de $0,25 \mathrm{~m}$ entre plantas e $0,90 \mathrm{~m}$ entre fileiras.

A adubação de base foi composta por $300 \mathrm{~kg} \cdot \mathrm{ha}^{-1}$ de adubo químico na fórmula 05-20-20, além de $135 \mathrm{~kg}$ ha ${ }^{-1} \mathrm{de} \mathrm{N}$ em cobertura na forma de uréia no estádio V6 nos dois anos experimentais.

O controle de plantas invasoras foi realizado quando necessário por capina manual e para controle de insetos-praga usou-se da aplicação de duas doses de inseticida com princípio ativo metamidofos, durante os estádios V3 e V5 do milho. Não se efetuou aplicações de fungicida em ambos os anos. A colheita foi realizada de forma manual no estádio reprodutivo R6, correspondente a maturidade fisiológica dos grãos. 
A determinação dos estádios fenológicos foi através da contagem diária do número de folhas completamente expandidas (com o colar visível, NFE) (STRECK et al., 2009). Anotou-se e fez-se a contagem do número de folhas em observações visuais da semeadura até a abertura de todas (fase vegetativa $-50 \%$ de folhas totalmente expandidas) marcando-se cada uma com fio de algodão para evitar o confundimento de estádios.

A mensuração foi realizada até a emissão da última folha, correspondendo ao estádio de pendoamento (VT). A colheita em ambos os anos foi realizada no estádio reprodutivo R6, correspondente a maturidade fisiológica dos grãos.

Foram feitas avaliações de comprimento da folha $(\mathrm{cm})$, a partir da inserção do colmo até seu ápice com régua graduada; largura de folha $(\mathrm{cm})$, avaliado no terço foliar médio com régua graduada; altura de planta $(\mathrm{cm})$, mensurada com régua graduada do nível do solo até o ápice da folha bandeira da planta completamente expandida; área foliar por estádio vegetativo, o cálculo da área foliar por estádio vegetativo foi dado através da fórmula: $\mathrm{AF}$ : $\left(\left(\mathrm{CF}^{*} \mathrm{LF}\right)^{*} \mathrm{C}\right)$, onde $\mathrm{AF}$ : Área

\section{RESULTADOS E DISCUSSÃO}

Os genótipos de ciclo superprecoce, precoce e tardio avaliados nos anos 1 e 2 apresentam arquitetura foliar de pentágono irregular invertido (Figura 1). O maior incremento em área foliar ocorre a partir do estágio V10 em populações crioulas para os diferentes ciclos. Para Vieira et al. (2006) a maioria dos híbridos de milho avaliados apresentaram arquitetura foliar na forma de pentágono regular. Essa diferença de arquitetura foliar se deve pela forma que foram feitas as representações, uma vez que, para o presente trabalho foram feitas medições constantes após cada folha emitida, diferentemente do trabalho citado que a representação foi feita com base na arquitetura foliar no final do ciclo do milho.

As áreas foliares máximas medidas

para o primeiro ano dos ciclos foliar, CF: comprimento de folha, LF: largura de folha, $\mathrm{C}$ : coeficiente de forma para área foliar do milho; altura de inserção espiga $(\mathrm{m})$, mensurada com auxílio de régua graduada a partir do nível do solo até a inserção inferior da espiga; comprimento e ramificações do pendão (cm), realizado com auxílio de régua graduada a partir da inserção da última folha aberta até o ápice do pendão com contagem das ramificações manualmente; comprimento de internódios $(\mathrm{cm})$, mensurados a $1 \mathrm{~m}$ de altura em relação ao nível do solo; diâmetro do colmo (mm): realizado com o auxílio de um paquímetro digital, mensurado duas repetições, no segundo internódio a partir do nível do solo, por planta de avaliação.

A área foliar foi calculada através da utilização do comprimento e largura da folha e um fator de correção 0,75 , que é mais indicado para genótipos de clima tropical e subtropical, no qual predominam (BAMPI et al., 2012).

Os dados coletados foram submetidos à análise de variância pelo programa estatístico R (2016), ao grau de significância de $5 \%$ de erro pelo teste de Tukey.

superprecoce, precoce e tardio foram $838,36 \mathrm{~cm}^{2}, 637,85 \mathrm{~cm}^{2}$ e $716,37 \mathrm{~cm}^{2}$ respectivamente, para o segundo ano foram $824,75 \mathrm{~cm}^{2}, 870,82 \mathrm{~cm}^{2}$ e $894,86 \mathrm{~cm}^{2}$. A média das menores áreas foliares para os ciclos superprecoce, precoce e tardio foram $15,24 \mathrm{~cm}^{2}, 15,03 \mathrm{~cm}^{2}$ e $16,29 \mathrm{~cm}^{2}$ respectivamente. Em estudo realizado por Vieira et al. (2006) encontraram área foliar máxima estimada para o genótipo de $905,63 \mathrm{~cm}^{2}$.

Para o ano 2 ocorreu maior incremento em área foliar para os ciclos superprecoce, precoce e tardio, em relação ao ano 1 (Figura 2). De acordo com o balanço hídrico do período esse maior incremento em área foliar para o ano 2 é resultante da maior disponibilidade de água para a fase de desenvolvimento da cultura na qual compreende os dois primeiros 
meses desde o plantio, nesse período a área

foliar está praticamente formada. Possivelmente essa maior área foliar em ano que ocorreu um período com balanço negativo se deve a data de plantio, que nesse ano, foi tardada.

A cultura do milho é muito sensível ao estresse hídrico, por afetar processos fisiológicos o que resulta em diminuição de sua área foliar e consequentemente a produção final. Alguns trabalhos mostram que quanto mais se tarda a data de semeadura de culturas como, milho (VILHEGAS et al., 2001) e arroz (ROSA et al., 2015; RIBAS et al., 2016), após a época considerada preferencial para uma dada região, ocorre diminuição na produção de grãos em função da variação nos elementos climáticos, tais como precipitação, radiação solar e temperatura (VILHEGAS et al., 2001). Estudo realizado por Vilhegas et al. (2001) trazem que a área foliar diminuiu quando se tardou a semeadura e a redução de área foliar poderia estar atrelada ao estresse hídrico que ocorreu durante o desenvolvimento vegetativo das plantas.
O milho é uma espécie que apresenta mecanismo fotossintético $\mathrm{C} 4$, fazendo com que as plantas expressem elevada produtividade quando apresentam maior área foliar e essa coincida com a disponibilidade de radiação solar e presença de água (KUNZ et al., 2007; ALVIM et al., 2011). A cultura do milho exige aproximadamente $450 \mathrm{~mm}$ de precipitação em todo seu ciclo. Se observarmos a média geral de área foliar dos dois anos agrícolas afirmamos que a área foliar é afetada pela disponibilidade hídrica, pois o ano dois inicialmente apresentou maior incremento em área foliar até o período de 16 folhas expandidas, diminuindo e sendo menor a partir desse período comparado com o ano um (Figura 3). A média geral de área foliar maior para o ano dois foi pela maior disponibilidade de água nos dois primeiros meses o que fez com que as plantas tivessem um maior arranque inicial e o posterior déficit hídrico diminuiu a área foliar, porém não afetou os componentes. 

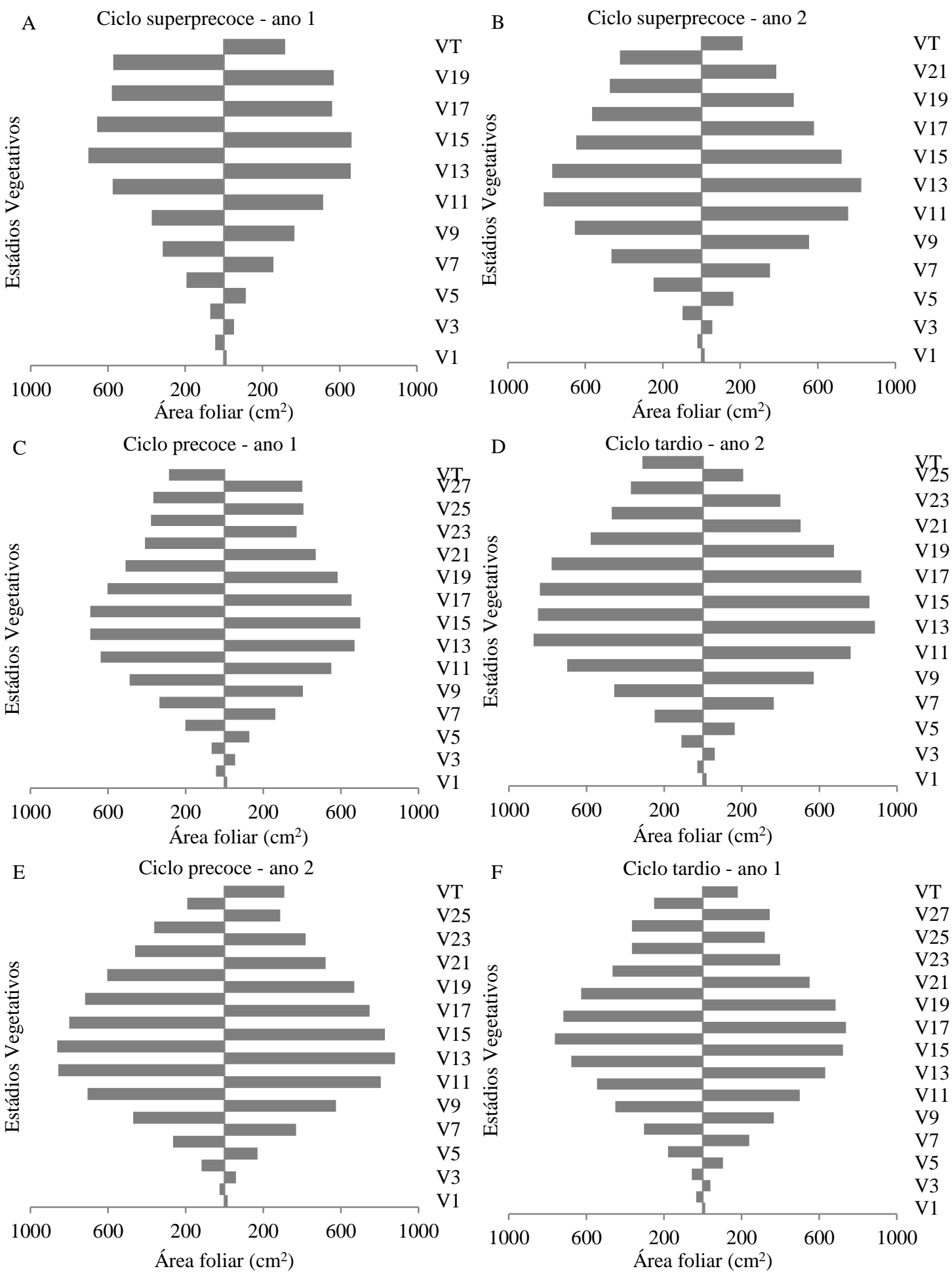

Figura 1: Representação da arquitetura foliar de populações de milho de ciclo superprecoce $(\mathrm{A}$ e $\mathrm{B})$, precoce $(\mathrm{C}$ e $\mathrm{D})$ e tardio $(\mathrm{E}$ e $\mathrm{F})$, em seus diferentes estádios vegetativos. 


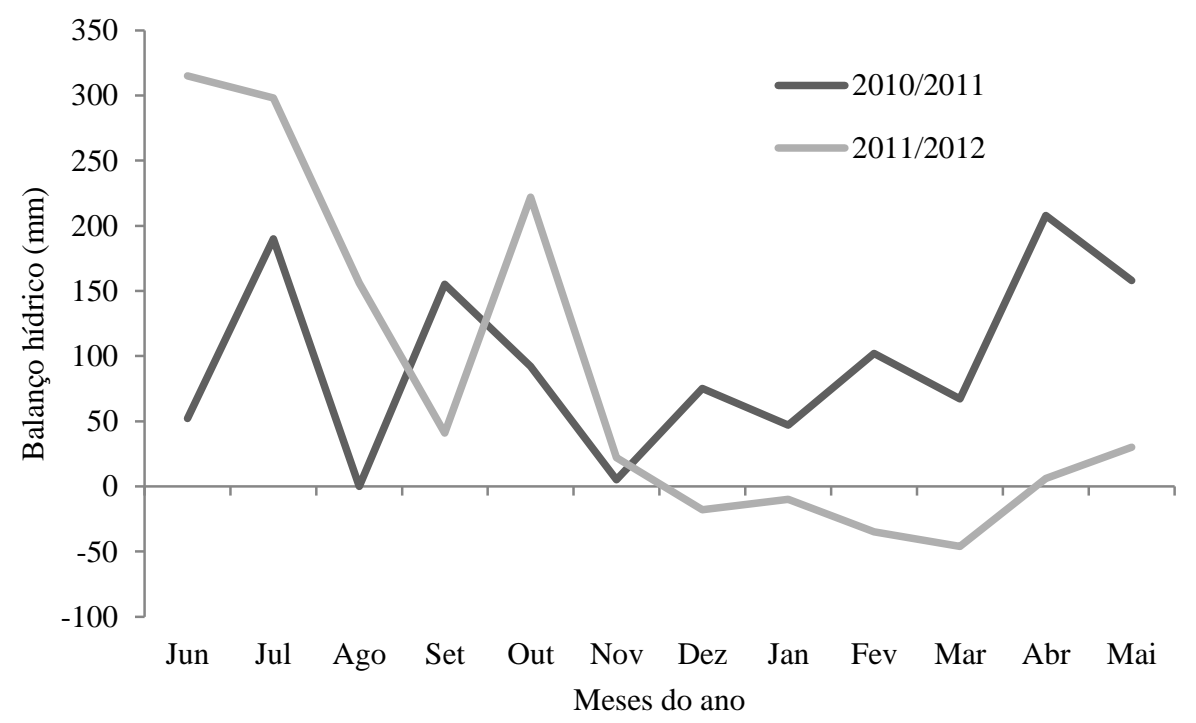

Figura 2: Balanço hídrico mensal correspondente aos dois anos de cultivo de populações de milho.

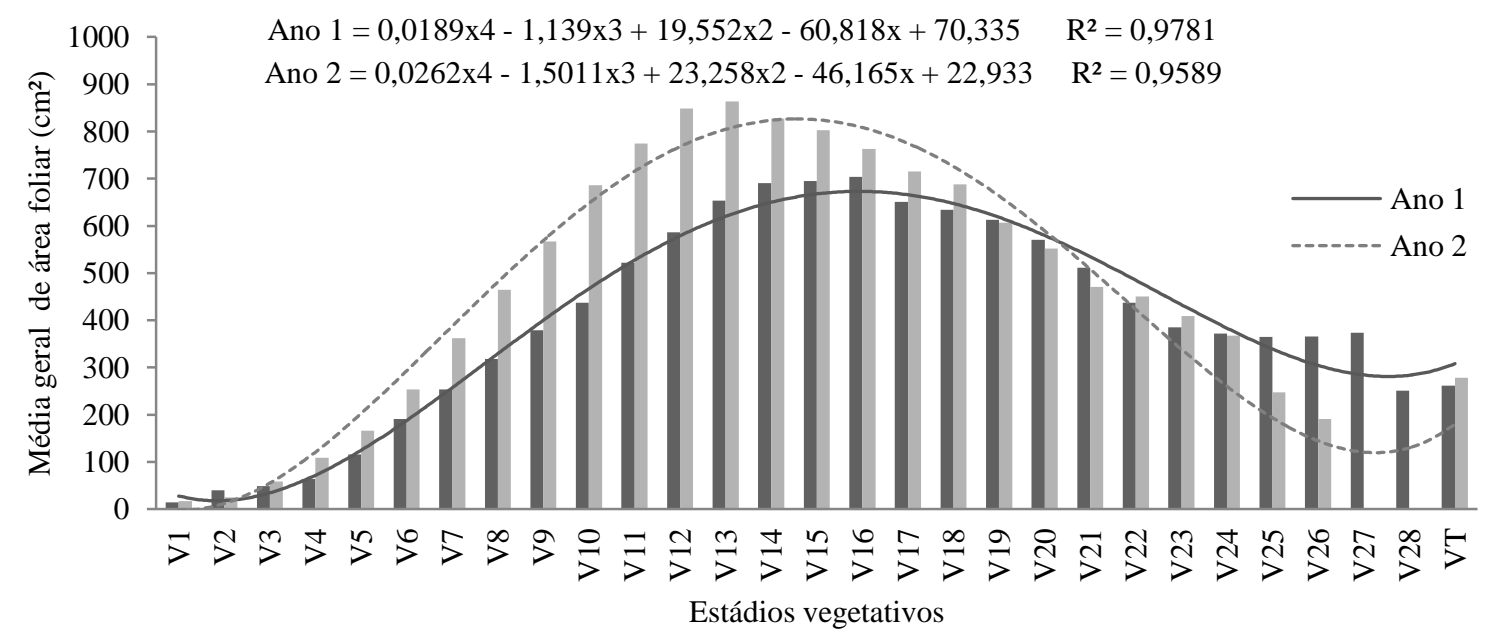

Figura 3: Média geral de área foliar os anos agrícolas 2010-2011 (Ano 1) e 2011-2012 (Ano 2) para a cultura do milho

O estádio V20 é representado pelo cruzamento das linhas, sendo que até esse ponto o ano 2 apresentou maior incremento em área foliar comparado com o ano 1 , sendo que até esse período se teve maior disponibilidade hídrica para o segundo ano, a partir de V20 o déficit hídrico fez com que a planta com a ação do ácido abscísico (ABA) fechasse os estômatos e retardasse seu desenvolvimento, dessa forma tendo queda na área foliar. A partir de V20 para o primeiro ano se observou a presença de água fazendo com que aumentasse a área foliar nesse período.

Em condições de baixa disponibilidade hídrica as concentrações de
ABA na planta aumentam, regulando a abertura e o fechamento dos estômatos. Seu acúmulo em folhas estressadas proporciona redução da perda de água pela transpiração (TAIZ et al, 2017). O déficit hídrico no período vegetativo das culturas reduz a área foliar, a taxa fotossintética e a acumulação de carboidratos. Nas fases iniciais V5, V6, pode ocasionar diminuição no potencial produtivo, pois é nessa fase que ocorre a diferenciação floral (ARAUS et al., 2011)

A inserção da espiga, bem como a distância do internódio e o diâmetro do colmo também fazem parte da arquitetura foliar da planta, para a inserção da espiga, 
os genótipos de ciclo tardio emitiram a espiga com 150,5 cm de altura em média, bem maior comparado com os demais ciclos (Tabela 1).

Tabela 1: Inserção da espiga $(\mathrm{cm})$, diâmetro do internódio $(\mathrm{cm})$ e diâmetro do colmo $(\mathrm{mm})$ em populações de milho de ciclo superprecoce (1), precoce (2) e tardio (3).

\begin{tabular}{lcccccc}
\hline & \multicolumn{2}{c}{ Inserção da espiga } & \multicolumn{2}{c}{ Distância do internódio } & \multicolumn{2}{c}{ Diâmetro do colmo } \\
\hline Ciclo & Ano 1 & Ano 2 & Ano 1 & Ano 2 & Ano 1 & Ano 2 \\
\hline 1 & $130,69 \mathrm{aA}$ & $137,86 \mathrm{bA}$ & $14,21 \mathrm{bB}$ & $18,57 \mathrm{bA}$ & $22,88 \mathrm{aB}$ & $26,93 \mathrm{bA}$ \\
2 & $140,27 \mathrm{aA}$ & $153,31 \mathrm{bA}$ & $14,83 \mathrm{bA}$ & $18,90 \mathrm{bA}$ & $22,30 \mathrm{aB}$ & $29,18 \mathrm{aA}$ \\
3 & $150,27 \mathrm{aB}$ & $188,67 \mathrm{aA}$ & $17,03 \mathrm{aB}$ & $21,81 \mathrm{aA}$ & $24,79 \mathrm{aB}$ & $29,58 \mathrm{aA}$ \\
\hline
\end{tabular}

Médias seguidas de mesma letra minúscula na coluna não diferem entre si pelo teste de tukey a 5\% de probabilidade de erro. Médias com letras maiúsculas representam as linhas

A distância do internódio também foi maior nos genótipos de ciclo tardio, comparado com os genótipos de ciclo precoce e superprecoce. Já para o diâmetro do colmo não teve diferença em relação aos diferentes ciclos, a variação que ocorreu de um ano para outro é em relação à disponibilidade hídrica.

$\mathrm{O}$ ano 1 embora tivesse apresentado maior disponibilidade hídrica

\section{CONCLUSÕES}

A arquitetura foliar de populações crioulas é representada por um pentágono irregular invertido. A disponibilidade de água no solo afeta diretamente a área foliar

\section{REFERÊNCIAS}

ALVARES, C.A.; STAPE, J.L.; SENTELHAS, P.C.; GONÇALVES, J.L.M.; SPAROVEK, G. Ko“ppen's climate classification map for Brazil. Meteorologische Zeitschrift, v.22(6): 711-728, 2014.

ARAUS, J.L.; SÁNCHEZ, C.; EDEMEADES, G.O. Phenotyping maize for adaption to drought. In: MONNEVEUX, P.; RIBAUT, J.M. (Ed.). Drought phenotyping in crops: from theory to practice. Texcoco: CGIAR Generation Challenge Programme: 263283, 2011.

ALVIM, K.R.T.; BRITO, C.H.; BRANDÃO, A.M.; GOMES, L.S.; LOPES, M.T.G. Redução da área foliar em obteve para todas as características valores menores, mas isso está atrelado a data de plantio que para o ano 1 foi em dezembro e para o ano 2 em setembro. Lembrando que a disponibilidade hídrica é fundamental na fase vegetativa, pois é nesse período que ocorre a definição do potencial produtivo da planta.

principalmente no período vegetativo e consequentemente componentes como diâmetro do colmo, distância de internódios.

plantas de milho na fase reprodutiva. Revista Ceres, v. 58(4): 413-418, 2011.

BAMPI, D.; CASA, R.T.; BOGO, A.; SANGOI, L.; SACHS, C.; BOLZAN, J.M.; PILETTI, G. Desempenho de fungicidas no controle da mancha-demacrospora na cultura do milho. Summa Phytopathologica, v. 38(4): 319-322, 2012.

BRACHTVOGEL, E.L.; PEREIRA, F.R.S.; CRUZ, S.C.S.; BICUDO, S.J. Maize plant densities in conventional and equidistant plant spacing. Ciência Rural, v. 39(8): 2334-2339, 2009.

DEPRÁ, M.S.; LOPES, S.J.; NOAL, G.; REINIGER, L.R.S.; COCCO, D.T. Modelo 
logístico de crescimento de cultivares crioulas de milho e de progênies de meiosirmãos maternos em função da soma térmica. Ciência Rural, v. 46(1): 36-43, 2016.

ENDRES, L.; SOUZA, J.L.; TEODORO, I.; MARROQUIM, G.M.P.; SANTOS, C.M.; BRITO, J.D.E. Gas exchange alteration caused by water deficit during the bean reproductive stage. Revista Brasileira de Engenharia Agrícola e Ambiental, v. 14(1): 11-16, 2010.

GARCIA, A.; ANDRÉ, R.G.B.; GALBIATTI, J. A.; TANNOUS, S. Análise de crescimento de uma cultura de milho submetida a diferentes regimes hídricos. Revista Nucleus, v. 5(1), 2008.

KAPPES, C.; ARF, O.; ANDRADE, J.A.C. Produtividade do milho em condições de diferentes manejos do solo e de doses de nitrogênio. Revista Brasileira de Ciências do Solo, v. 37: 1310-1321, 2013.

KUNZ, J.H.; BERGONCI, J.I.; BERGAMASCHI, H.; DALMAGO, G.A.; HECKLER, B.M.M.; COMIRAN, F. Uso da radiação solar pelo milho sob diferentes preparos do solo, espaçamento e disponibilidade hídrica. Pesquisa Agropecuária Brasileira, v. 42(11): 15111520, 2007.

LIMA, S.F.; ALVAREZ, R.C.F.; CONTARDI, L.M. Influence of row spacing on agronomic parameters features and dry matter accumulation of maize hybrids. Ambiência, v. 12(4): 1027-1039, 2016.

MARTINS, J.D.; CARLESSO, R.; PETRY, M.T.; KNIES, A.E.; OLIVEIRA, Z.B.; BROETTO, T. Estimativa do filocrono em milho para híbridos com diferentes ciclos de desenvolvimento Vegetativo. Ciência Rural, v. 42(5): 777783, 2012.
MENDES, M.M.S.; LACERDA, C.F.; CAVALCANTE, A.C.R.; FERNANDES, F.E.P.; OLIVEIRA, T.S. Desenvolvimento do milho sob influência de árvores de pau- branco em sistema agrossilvipastoril. Pesquisa Agropecuária Brasileira, v. 48(10): 1342-1350, 2013.

MUNDSTOCK, C. M. Densidade de semeadura no milho para o Rio Grande do Sul. Porto Alegre: UFRGS/ASCAR, 1977. $35 \mathrm{p}$.

NASCIMENTO, H.H.; NOGUEIRA, R.J.M.C.; SILVA, E.C.; SILVA, M.A. Análise do crescimento de mudas de jatobá (Hymenaea courbaril 1.) em diferentes níveis de água no solo. Revista Árvore, v. 35(3): 617-626, 2011.

OLIVEIRA, P.; NASCENTE, A.S.; KLUTHCOUSKI, J.; PORTES, T.A. Crescimento e produtividade de milho em função da cultura antecessora. Pesquisa Agropecuária Tropical, v. 43(3): 239246, 2013.

R Development Core Team. A language and environment for statistical computing. $\mathrm{R}$ Foundation for Statistical Computing, Vienna, Austria. URL http://www.Rproject.org, 2016.

REIS, L.S.; AZEVEDO, C.A.V.; ALBUQUERQUE, A.W.; JUNIOR, J.F.S. Índice de área foliar e produtividade do tomate sob condições de ambiente protegido. Revista Brasileira de Engenharia Agrícola e Ambiental, v. 17(4): 386-391, 2013.

RIBAS, G.G.; STRECK, N.A.; LAGO, I.; ZANON, A.J.; WALDOW, D.A.G.; DUARTE JUNIOR, A.L.; NASCIMENTO, M.F.; FONTANA, V. Acúmulo de matéria seca e produtividade em híbridos de arroz irrigado simulados com o modelo SimulArroz. Pesquisa Agropecuária Brasileira, v. 51(12): 19071917, 2016. 
ROSA, H.T.; WALTER, L.C.; STRECK, N.A.; DE CARLI, C.; RIBAS, G.G.; MARCHESAN, E. Simulação do crescimento e produtividade de arroz no Rio Grande do Sul pelo modelo Simul Arroz. Revista Brasileira de Engenharia Agrícola e Ambiental, v. 19(12): 1159$1165,2015$.

ROSSATO, M.S. Os climas do Rio Grande do Sul: Tendências e tipologias. In: Mendonça, F. (Org.). Os climas do Sul: Em tempos de mudanças climáticas globais. Jundiaí: Paco Editorial, 2014.

SANTOS, H. G.; JACOMINE, P. K. T.; ANJOS, L. H. C.; OLIVEIRA, V. A.; LUBRERAS, J. F.; COELHO, M. R.; ALMEIDA, J. A.; CUNHA, T. J. F.; OLIVEIRA, J. B. Sistema Brasileiro de Classificação de Solos. 3. ed. Brasília, EMBRAPA, 353p, 2013.

SILVA M.R.; MARTIN, T.N.; ORTIZ, S.; BERTONCELLI, P.; VONZ, D. Agronomic performance of maize genotypes under conditions of water restriction. Revista de Ciências Agrárias, v. 35, n.1, 2012.

STRECK, N.A.; LAGO, I.; SAMBORANHA, F.K.; GABRIEL, L.F.;
SCHWANTES, A.P.; SCHONS, A. Temperatura base para aparecimento de folhas e filocrono da variedade de milho BRS Missões. Ciência Rural, Santa Maria, v. 39(1); 224-227, 2009.

STRECK, N.A.; SCHWAB, N.T. The anthochron as a building block of flower development. Pesquisa Agropecuária Brasileira, Brasília, v. 51(8): 899-904, 2016.

TAIZ, L.; ZEIGER, E.; MOLLER, I.M.; MURPHY, A. Fisiologia vegetal. $6^{\mathrm{a}}$ ed. Porto Alegre: Artmed, 2017. 719 p.

VIEIRA, P.A.J.; NETO, D.D.; BERNARDES, M.S.; FANCELLI, A.; MANFRON, P.A.; MARTINS, T.N. Metodologia para estimativa da área foliar de genótipos de milho. Revista Brasileira de Milho e Sorgo, v. 5(2): 182-191, 2006.

VILHEGAS, A.C.G.; VIDIGAL FILHO, P.S.; SCAPIM, C.A.; VIDIGAL, M.C.G.; BRACCINI, A.L.; SAGRILO, E. Efeito de épocas de semeadura e estabilidade de híbridos de milho em plantios de safrinha no noroeste do paraná. Bragantia, v. 60(1): 45-51, 2001. 